\title{
A Comprehensive Study on Energy Absorption and Exposure Buildup Factors for some Soils and Ceramic Materials
}

\author{
Sandeep Gupta ${ }^{1}$, Gurdeep Singh Sidhu ${ }^{2}$ \\ ${ }^{1}$ Department of Physics, Singhania University, Rajasthan, India) \\ ${ }^{2}$ Government Sports School, Ghudda (Bathinda), India)
}

\begin{abstract}
Study of gamma ray energy absorption (EABF) and exposure buildup factors (EBF) for some essential soils, ceramic materials in the energy region 0.015-15 MeV up to a penetration depth of $40 \mathrm{mfp}$ (mean free path). To calculate both EABF and EBF, five parameter geometric progressions (G-P) fitting approximation has been used. Variation of EABF and EBF with incident photon energy, penetration depth and effective atomic number $\left(Z_{\text {eff }}\right)$ has been studied and presented in the form of graphs. This change results from the dominance of different interaction process in different energy regions. Significant variations were also observed between $E A B F$ and $E B F$ which may due to different chemical composition of given materials.
\end{abstract}

Keywords: Cascade silt loam (CSL), Energy absorption buildup factor, Exposure buildup factor, Kaolinite (KLN), Mica, Sand.

\section{Introduction}

Buildup factors are the shielding materials and geometry dependent parameters which correct the simple attenuation calculations so that they include the contribution of the radiation field produced by the collided part of beam. As far as application of buildup factors in practical shielding problems is concerned, these have been incorporated into a number of point kernel methods of dose calculations in the case of a variety of radiation sources. The concept of buildup factor was mutually introduced by White [1] and Fano [2] recognized its importance in attenuation studies. There are two type of buildup factor (a) the energy absorption buildup factor that is the buildup factor in which the quantity of interest is the absorbed or deposited energy in the interacting material and the detector response function is that of absorption in the interacting material. (b) the exposure buildup factor is the buildup factor in which the quantity of interest is the exposure and the detector response function is that of absorption in the air[3].There are different available methods to calculate the buildup factor such as G.P fitting method[4] and invariant embedding method[5]-[7]. Recently American National standards ANSI/ANS-6.4.3[8] has provided buildup factor data for 23 elements, one compound and two mixtures (i.e. air and water) and concrete at energies in the range $0.015-15 \mathrm{MeV}$ up to penetration depths of 40 mfp by using the G.P method. The developed G-P fitting formula is known to be accurate within a few percent error [4], [9]. Recently, Harima has made the excessive historical review and an assessment for the status of buildup factor calculations and applications [10]. The gamma ray transmission method has been reported as the most accurate and convenient techniques for non destructive measurements of soil parameters like moisture content, density etc. [11]. The composition of soils like sand and cascade silt loam has been taken from literature of Brady N.C. [12] and of ceramic materials like kaolinite and mica has been taken from literature of Bear F.E. [13]. There are successful contributions which are based on the buildup factor studies in some soils and ceramic materials available in the literature. For example, Brar et al. [14] have studied the variation of buildup factors of soils with weight fractions of iron and silicon. Sidhu et al. [15] have studied the energy and effective atomic number dependence of the exposure buildup factors in biological samples. Manohara et al. [16] studied the variation of exposure buildup factors for heavy metal oxide glass with photon energy and penetration depth. Singh et al. [17] studied the energy dependence of total photon attenuation coefficients of composite materials. In the present work, we study the EABF and EBF by using the G-P fitting method for some essential soils and ceramic materials in the energy region $0.015-15 \mathrm{MeV}$ up to penetration depth of $40 \mathrm{mfp}$. The generated EABF and EBF data have been studied as a function of incident energy, penetration depth and effective atomic number $\left(Z_{\text {eff }}\right)$. Also, the comparison of EABF and EBF has been made and significant variation was noted.

\section{Computational work}

To calculate the buildup factors, the G-P fitting parameters were obtained by the method of interpolations from the equivalent atomic number $\left(\mathrm{Z}_{\mathrm{eq}}\right)$. Computations are illustrated step by step as follows:

2.1. Calculation of the equivalent atomic number $Z_{\text {eq }}$

2.2. Calculation of geometric progression (G-P fitting parameters)

2.3. Calculation of energy absorption and exposure buildup factors 
Table1 Chemical Composition $(\%)$ by Weight for

\begin{tabular}{|c|c|c|}
\hline \multicolumn{3}{|c|}{ Chosen Materials } \\
\hline Composition & Sand & $\begin{array}{l}\text { Cascade Silt } \\
\text { Loam }\end{array}$ \\
\hline $\mathrm{SiO}_{2}$ & 91.49 & 70.40 \\
\hline $\mathrm{TiO}_{2}$ & 0.50 & 1.08 \\
\hline $\mathrm{Fe}_{2} \mathrm{O}_{3}$ & 1.75 & 3.90 \\
\hline $\mathrm{Al}_{2} \mathrm{O}_{3}$ & 4.51 & 13.14 \\
\hline $\mathrm{MnO}$ & 0.007 & 0.07 \\
\hline $\mathrm{CaO}$ & 0.01 & 1.78 \\
\hline $\mathrm{MgO}$ & 0.02 & 0.97 \\
\hline $\mathrm{K}_{2} \mathrm{O}$ & 0.16 & 2.11 \\
\hline $\mathrm{Na}_{2} \mathrm{O}$ & - & 1.98 \\
\hline $\mathrm{P}_{2} \mathrm{O}_{5}$ & 0.05 & 0.16 \\
\hline $\mathrm{SO}_{3}$ & 0.05 & 0.21 \\
\hline Nitrogen & 0.02 & 0.08 \\
\hline
\end{tabular}

Table2 Equixalent Atomic Numbers of Different Soils in the Energy Range 0.015-15.0 MeV

\begin{tabular}{|c|c|c|}
\hline \multicolumn{3}{|c|}{ Soils } \\
\hline $\mathrm{E}(\mathrm{MeW})$ & Sand & $\begin{array}{c}\text { Cascade silt } \\
\text { loam }\end{array}$ \\
\hline $1500 \mathrm{E}-01$ & $.1267 \mathrm{E}-02$ & $.1274 \mathrm{E}+02$ \\
\hline $2000 \mathrm{E}-01$ & $.1278 E+02$ & $.1284 E+02$ \\
\hline $3000 \mathrm{E}-01$ & $.1291 \mathrm{E}+02$ & $.1297 \mathrm{E}+02$ \\
\hline $.4000 \mathrm{E}-01$ & $1300 \mathrm{E}-02$ & $.1306 \mathrm{E}+02$ \\
\hline $.5000 \mathrm{E}-01$ & $.1309 \mathrm{E}-02$ & $.1317 \mathrm{E}-02$ \\
\hline $.6000 \mathrm{E}-01$ & $.1313 \mathrm{E}+02$ & $1322 \mathrm{E}+02$ \\
\hline $.8000 \mathrm{E}-01$ & $.1311 E+02$ & $.1329 E-02$ \\
\hline $1000 \mathrm{E}-00$ & $1336 \mathrm{E}-02$ & $.1336 \mathrm{E}+02$ \\
\hline $.1500 \mathrm{E}+00$ & $.1344 E+02$ & $.1344 E+02$ \\
\hline $.2000 \mathrm{E}+00$ & $.1292 \mathrm{E}+02$ & $.1449 \mathrm{E}+02$ \\
\hline $3000 \mathrm{E}-00$ & $.1250 \mathrm{E}+02$ & $1450 \mathrm{E}+02$ \\
\hline $.4000 \mathrm{E}+00$ & $.1250 E-02$ & $.1450 \mathrm{E}-02$ \\
\hline $.5000 \mathrm{E}-00$ & $.1250 \mathrm{E}+02$ & $.1450 \mathrm{E}+02$ \\
\hline $.6000 E-00$ & $1250 \mathrm{E}-02$ & $.1450 \mathrm{E}+02$ \\
\hline $8000 E+00$ & $.1250 E+02$ & $1450 E+02$ \\
\hline $.1000 \mathrm{E}+01$ & $.1250 \mathrm{E}+02$ & $.1450 \mathrm{E}+02$ \\
\hline $1500 \mathrm{E}-01$ & $.1250 \mathrm{E}+02$ & $1450 \mathrm{E}-02$ \\
\hline $2000 \mathrm{E}+01$ & $.9741 \mathrm{E}-01$ & $9757 \mathrm{E}-01$ \\
\hline $3000 \mathrm{E}-01$ & $1159 \mathrm{E}+02$ & $.1071 \mathrm{E}+02$ \\
\hline $.4000 \mathrm{E}-01$ & $1096 \mathrm{E}+02$ & $.1146 \mathrm{E}+02$ \\
\hline $.5000 E-01$ & $1117 \mathrm{E}+02$ & $.1161 \mathrm{E}-02$ \\
\hline $6000 E-01$ & $.1127 \mathrm{E}+02$ & $.1152 \mathrm{E}-02$ \\
\hline $8000 E-01$ & $.1144 \mathrm{E}-02$ & $.1178 \mathrm{E}-02$ \\
\hline $1000 E-02$ & $.1136 \mathrm{E}+02$ & $1136 \mathrm{E}+02$ \\
\hline $1500 \mathrm{E}+02$ & $1149 \mathrm{E}-02$ & $.1149 \mathrm{E}+02$ \\
\hline
\end{tabular}

Table 3 Chemical Formula of Chosen Ceramic Material

\begin{tabular}{|c|c|}
\hline Ceramics & $\begin{array}{l}\text { Chemical } \\
\text { Formula }\end{array}$ \\
\hline Kaolinite & $\mathrm{Si}_{4} \mathrm{Al}_{4} \mathrm{O}_{10}(\mathrm{OH})_{8}$ \\
\hline Mica & $\mathrm{K}_{2} \mathrm{Al}_{2} \mathrm{Si}_{6} \mathrm{Al}_{4} \mathrm{O}_{20}(\mathrm{OH})_{4}$ \\
\hline
\end{tabular}

Table 4 Equivalent Atomic Numbers of Different Ceramic Materials in the Energy Range $0.015-15.0 \mathrm{MeV}$

\begin{tabular}{|c|c|c|}
\hline \multicolumn{3}{|c|}{ Ceramic materials } \\
\hline $\mathrm{E}(\mathrm{MeV})$ & Mica & Kaolinite \\
\hline $.1500 \mathrm{E}-01$ & $.1338 E-02$ & $1092 E+02$ \\
\hline $.2000 \mathrm{E}-01^{-}$ & $.1343 E+02$ & $.1097 \mathrm{E}+02$ \\
\hline $.3000 \mathrm{E}-01$ & $.1343 E+02$ & $.1102 E+02$ \\
\hline $.4000 \mathrm{E}-01^{-}$ & $.1344 \mathrm{E}+02$ & $.1106 E+02$ \\
\hline $.3000 \mathrm{E}-01$ & $1348 \mathrm{E}+02$ & $.1112 \mathrm{E}+02$ \\
\hline $.6000 \mathrm{E}-01$ & $1352 \mathrm{E}+02$ & $1109 E+02$ \\
\hline $.8000 \mathrm{E}-01$ & $.1339 \mathrm{E}+02$ & $.1122 E+02$ \\
\hline $.1000 E+00$ & $.1338 E+02$ & $.1132 E+02$ \\
\hline $.1500 \mathrm{E}+00$ & $.1347 E+02$ & $.1088 \mathrm{E}+02$ \\
\hline $.2000 E+00$ & $.1293 E+02$ & $.1290 E+02$ \\
\hline $.3000 \mathrm{E}+00$ & $.1250 E+02$ & $.1250 \mathrm{E}+02$ \\
\hline $.4000 E-00$ & $.1250 E+02$ & $1250 \mathrm{E}+02$ \\
\hline $.5000 E+00$ & $.1250 E+02$ & $1250 \mathrm{E}+02$ \\
\hline $.6000 E+00$ & $.1250 E+02$ & $.1250 \mathrm{E}+02$ \\
\hline $.8000 E+00$ & $.1250 \mathrm{E}+02$ & $.1250 E+02$ \\
\hline $.1000 E+01$ & $.1250 \mathrm{E}+02$ & $.1250 \mathrm{E}+02$ \\
\hline $1500 E-01$ & $.1250 E+02$ & $1250 \mathrm{E}+02$ \\
\hline $.2000 E+01$ & $.1288 \mathrm{E}+02$ & $.8703 E+01$ \\
\hline $3000 E-01$ & $.1316 E+02$ & $9774 E+01$ \\
\hline $.4000 \mathrm{E}+01$ & $1266 \mathrm{E}+02$ & $9810 \mathrm{E}+01$ \\
\hline $.3000 E+01$ & $.1297 E+02$ & $1009 E+02$ \\
\hline $.6000 \mathrm{E}+01$ & $.1312 E+02$ & $.1006 \mathrm{E}+02$ \\
\hline $.8000 E+01$ & $.1299 \mathrm{E}+02$ & $1003 \mathrm{E}+02$ \\
\hline $.1000 E+02$ & $.1289 E-02$ & $1014 E+02$ \\
\hline $.1500 \mathrm{E}+02$ & $.1312 E+02$ & $.1005 \mathrm{E}+02$ \\
\hline
\end{tabular}

The equivalent atomic number, $\mathrm{Z}_{\mathrm{eq}}$ is a parameter describing the properties of the composite materials in terms of equivalent elements, hence it is similar to that atomic number of element. Hence the interaction of gamma rays with materials is based on domination of different partial photon interaction processes in different energy regions, thus $Z_{\text {eq }}$ is an energy dependent parameter. Since the buildup factor mainly arises from multiple scattering events, $Z_{\mathrm{eq}}$ is derived from the contribution of Compton scattering process.

At the first step, the equivalent atomic number $Z_{\text {eq }}$ for particular material has been calculated by

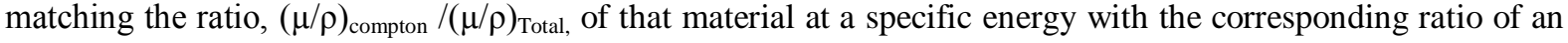


element at the same energy. Thus, firstly the Compton partial mass attenuation coefficient, $(\mu / \rho)_{\text {Compton }}$, and the total mass attenuation coefficients, $(\mu / \rho)_{\text {Total }}$, were obtained for the elements of $Z=4-40$ and for the soils and ceramic materials in the energy region $0.015-15 \mathrm{MeV}$, using the XCOM [18] computer program. For the interpolation of $Z_{\mathrm{eq}}$ for which the ratio $(\mu / \rho)_{\text {compton }} /(\mu / \rho)_{\text {Total }}$ lies between two successive ratios of elements, the following formula has been employed [16]:

$$
Z_{\text {eq }}=\frac{Z_{1}\left(\log R_{2}-\log R\right)+Z_{2}\left(\log R-\log R_{1}\right)}{\log R_{2}-\log R_{1}}
$$

Where $Z_{1}$ and $Z_{2}$ are the elemental atomic numbers corresponding to the ratios $(\mu / \rho)_{\text {compton }} /(\mu / \rho)_{\text {Tot, }} R_{1}$ and $R_{2}$ respectively, and $R$ are the ratio for given soils and ceramic materials at a particular energy. The value of $\mathrm{Z}_{\mathrm{eq}}$ for the selected soils and ceramic materials so obtained are given in Table 3 and 4.

In the second step, to calculate the G-P fitting parameter a similar interpolation procedure was adopted as in the case of the equivalent atomic number. The G-P fitting parameter for elements were taken from the ANSI/ANS6.4.3[8] standard reference data base which provides the G-P fitting parameters for elements from beryllium to iron in the energy region $0.015-15 \mathrm{MeV}$ up to $40 \mathrm{mfp}$. Formula given below is used in interpolation of G-P fitting buildup coefficient of the used materials:

$$
C=\frac{C_{1}\left(\log Z_{2}-\log Z_{e q}\right)+C_{2}\left(\log Z_{e q}-\log Z_{1}\right)}{\log Z_{2}-\log Z_{1}}
$$

Where $\mathrm{C}_{1}$ and $\mathrm{C}_{2}$ are the values of coefficients (G-P fitting parameters) corresponding to the atomic numbers of $Z_{1}$ and $Z_{2}$ respectively, at a given energy and $Z_{\text {eq }}$ is the equivalent atomic number of the given material.

At the final step, The G.P fitting parameters were then used to generate energy absorption and exposure buildup factor data for these materials using the following G.P fitting formula given by Harima et al.[4]

$B(E, x)=1+\frac{(b-1)\left(K^{x}-1\right)}{K-1}$ for $\mathrm{K} \neq 1$

$\mathrm{B}(\mathrm{E}, \mathrm{x})=1+(\mathrm{b}-1) \mathrm{x} \quad$ for $\mathrm{K}=1$

Where

$$
K(E, x)=c x^{a}+d \frac{\tanh \left(x / X_{k}-2\right)-\tanh (-2)}{1-\tanh (-2)} \quad \text { for } x \leq 40 m f p
$$

Where $\mathrm{E}$ is the incident photon energy, $\mathrm{x}$ is the penetration depth in mean free path, a,b,c,d and $\mathrm{X}_{\mathrm{k}}$ are the G-P fitting parameters and $\mathrm{b}$ is the value of buildup factor at $1 \mathrm{mfp}$. The parameter $\mathrm{K}(\mathrm{E}, \mathrm{x})$ is the photon dose multiplication factor and change in the shape of the spectrum. Here the mean free path (mfp) is defined as the average distance that photons of a given energy travel before an two successive interactions in a given medium occur. It is equal to the reciprocal of the attenuation coefficient. The ratio of the total value of a specified radiation quantity at any point to the contribution to that value from radiation reaching the point without having undergone any collision is called "buildup factor".

\section{Result and Discussion}

The chemical composition of soils is listed in Table 1 and Chemical formulas of ceramic materials are listed in Table 2. Table 3 and 4 shows the obtained equivalent atomic numbers of the material listed above. The EABF and EBF have been shown in graphical form at fixed penetration depth (Figs. 1(a) to 4(a), (b) ) as well as at fixed energy values (Figs. 5 to 8). Figs. 9(a, b) and 10(a, b) shows the variation of EABF and EBF with effective atomic number $\left(Z_{\text {eff }}\right)$ for different energies at penetration depth of $15 \mathrm{mfp}$. Fig. 11(a) and (b) shows the relative difference between ANSI [8] database and the present work with respect to the calculated values of $\mathrm{EABF}$ and EBF for air. In the following subsections, various figures mentioned above are analyzed.

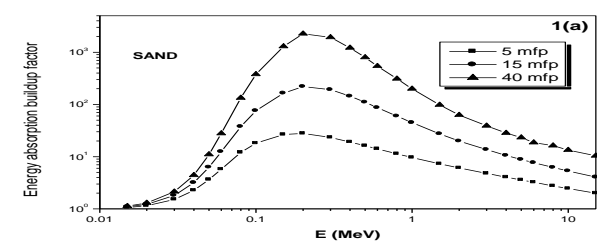

Fig. 1 (a) The EABF for sand in the energy region $0.015-15 \mathrm{MeV}$ at $5,15,40 \mathrm{mfp}$

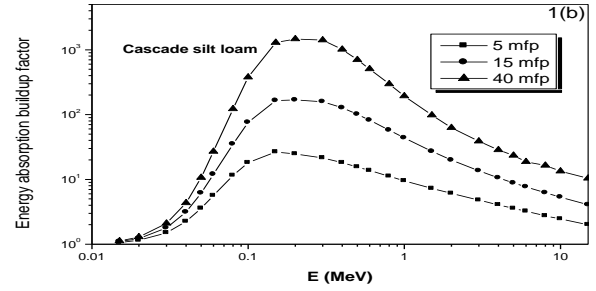

Fig. 1 (b) The EABF for cascade silt loam in the energy region $0.015-15 \mathrm{MeV}$ at $5,15,40 \mathrm{mfp}$ 

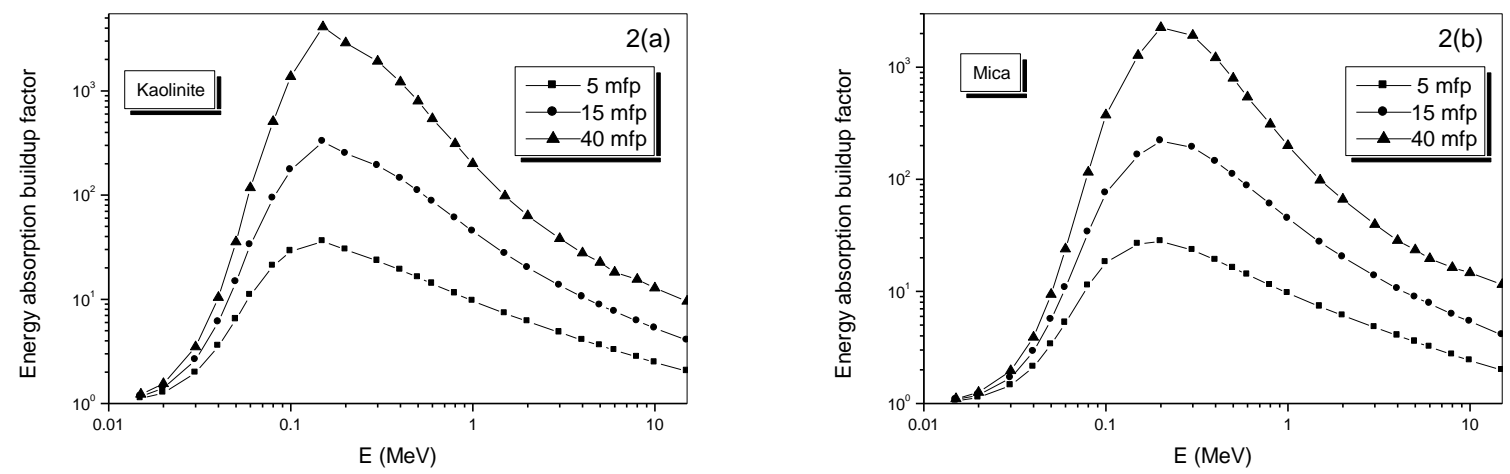

Fig. 2(a), (b) The EABF for Kaolinite and Mica in the energy region $0.015-15 \mathrm{MeV}$ at 5, 15, 40mfp
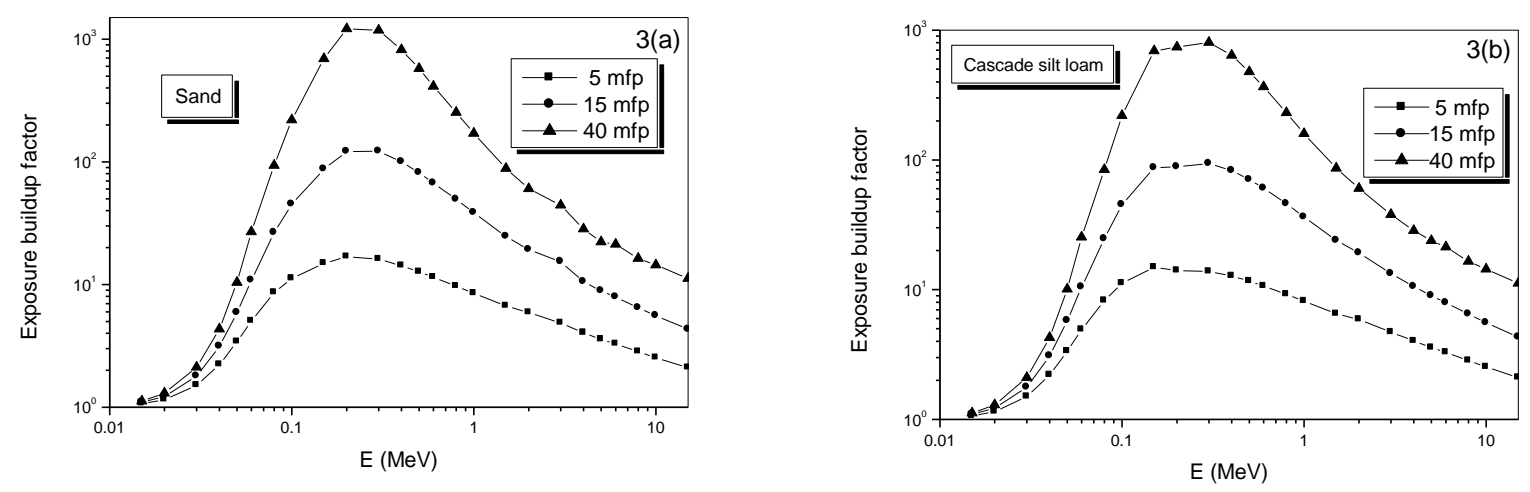

Fig. 3(a, b) The EBF for Sand and Cascade silt loam in energy region 0.015-15 MeV at 5, 15,40 mfp

\subsection{EABF and EBF of Soils and Ceramic Materials \\ 3.1.1 Effect of Incident Photon Energy on EABF and EBF}

From Figs. 1 to 4(a,b) it has been observed that EABF and EBF values of soils and ceramic materials start increasing with increase in photon energy up to a maximum energy at intermediate energies and then further start decreasing with increase in energy of gamma ray. Here the low value of buildup factor around $0.015 \mathrm{MeV}$ is due to predominance of photo electric effect in this energy region which results in fast removal of low energy photons, thereby not allowing these photons to buildup. It is further observed that in the energy range $0.15 \mathrm{MeV}$ to $0.8 \mathrm{MeV}$ the buildup factor values are high for a given penetration depth due to dominance of Compton effect. Which only helps in the degradation of photon energy and fails to remove a photon completely. Because of multiple scattering of photons they exist for longer time in material which leads to a higher value of buildup factor. Here it is also observed that at gamma ray energy $0.2 \mathrm{MeV}$, buildup factor value is very high because of exclusive dominance of Compton effect. Furthermore it is also observed that for energies greater than $2.0 \mathrm{MeV}$, the dominance of pair production phenomenon over Compton effect increases, so values of buildup factor decreases. The variation of EABF and EBF with incident photon energy seem to be independent of chemical composition of above materials beyond $2.0 \mathrm{MeV}$ respectively.
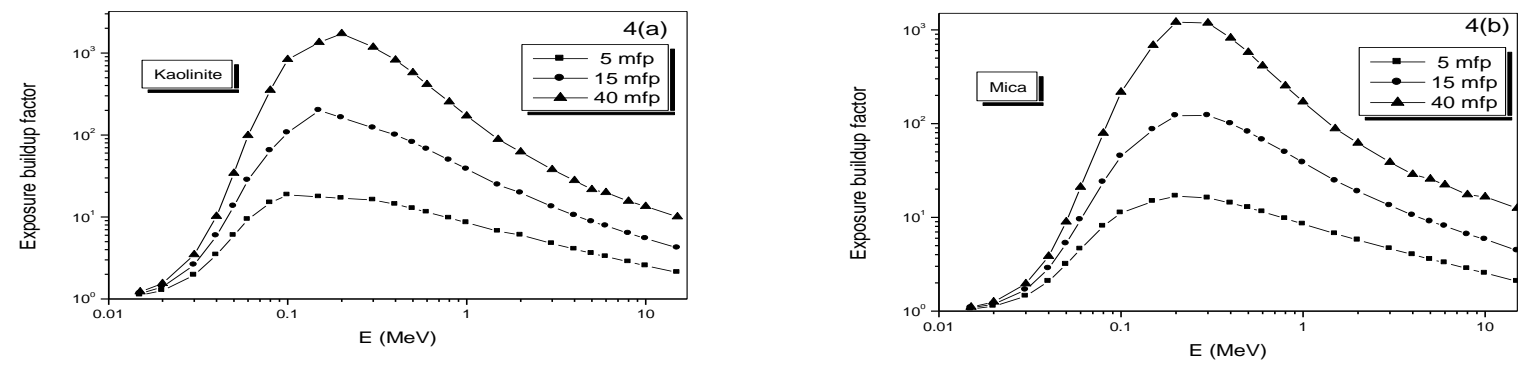

Fig. 4(a), (b) The EBF for Kaolinite and Mica in the energy region 0.015-15 MeV at 5, 15, 40mfp 


\subsubsection{Effect of Penetration Depth on EABF and EBF}

The values of EABF and EBF of soils and ceramic materials increase with the increase in penetration depth. At lowest photon energy $0.015 \mathrm{MeV}$ EABF and EBF values are low because of dominance of photoelectric effect, but at $0.2 \mathrm{MeV}$ photon energy EABF and EBF values are much higher due to dominance of Compton effect. It can also be seen, at photon energy 5 and $15 \mathrm{MeV}$ EABF and EBF values are low due to predominance of pair- production as in figs. 5 to 8 .

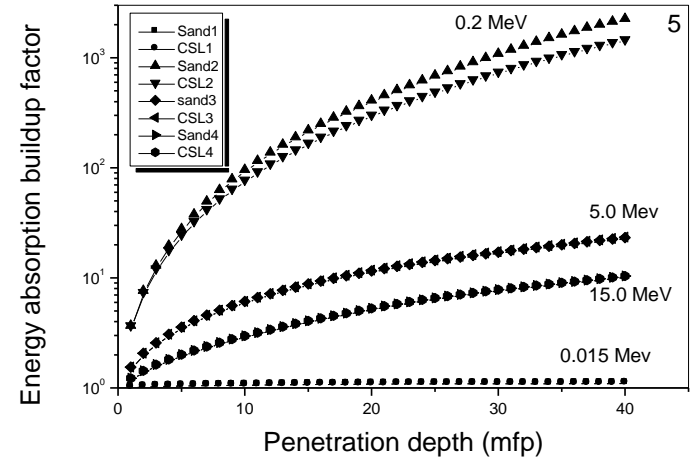

Fig. 5 The EABF for soils upto 40mfp at 0.015 , $0.2,5.0,15 \mathrm{MeV}$

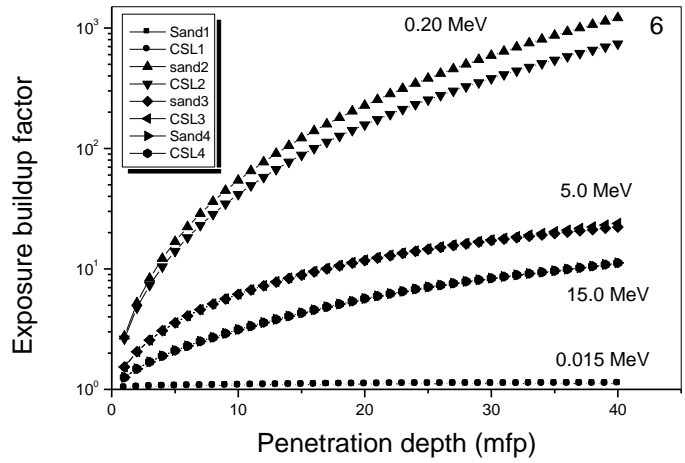

Fig.6 The EBF for soils upto 40mfp at 0.015, 0.2, $5.0,15 \mathrm{MeV}$

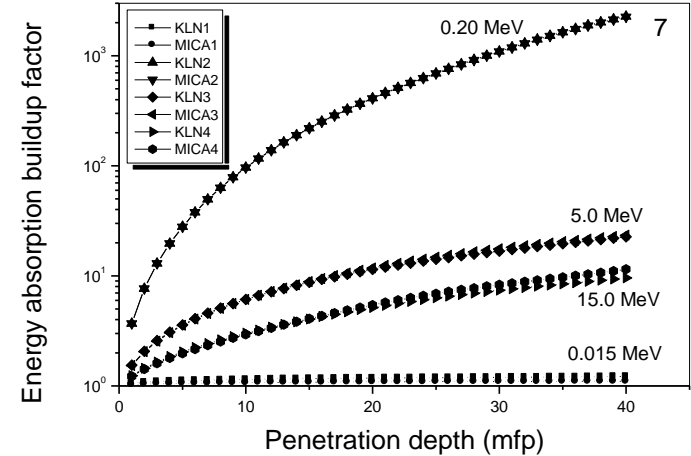

Fig.7 The EABF for ceramic materials up to $40 \mathrm{mfp}$ at $0.015,0.2,5.0,15 \mathrm{MeV}$

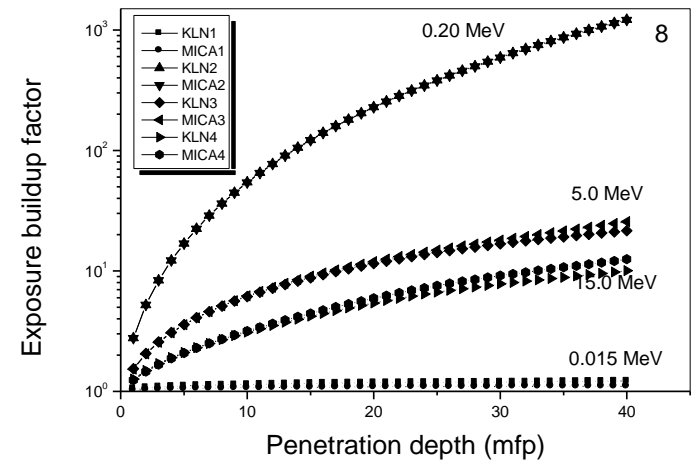

Fig. 8 The EBF for ceramic materials up to $40 \mathrm{mfp}$ at $0.015,0.2,5.0,15 \mathrm{MeV}$

From Figs. 5 to 8 we see at the lowest photon energy $0.015 \mathrm{MeV}$ the values of EABF and EBF is slightly more in case of sand than cascade silt loam, but in case of ceramic materials kaolinite with low $Z_{\text {eq }}$ value has much higher values of EABF and EBF than mica with higher value of $Z_{\mathrm{eq}}$.

At the photon energy $0.20 \mathrm{MeV}$ EABF and EBF of sand is more than cascade silt loam at penetration depth from 20 to $40 \mathrm{mfp}$. But EABF and EBF both are approximately same in case of kaolinite and mica as in Figs 7 and 8.. The variation of EABF and EBF of soils with increase in penetration depth is not affected by the chemical composition of material at higher energy range 5-15 MeV, but at that energy range EABF and EBF slightly differ of ceramic materials according to chemical composition .

However, the values of EABF and EBF of ceramic material increases with increase in penetration depth between 15 to $40 \mathrm{mfp}$ at energy range of 5-15 MeV. The reason behind the pair production process starts pre- dominating and results with an electron-positron pair for lower penetration depth, these particles may escape from the material or after multiple collisions with in the material comes to rest and further annihilates. With the increase in penetration depth, these secondary gamma rays (as a result of annihilation) contribute to the rise in intensity of the primary gamma rays [19].

\subsubsection{Effect of Effective Atomic Number on EABF and EBF}

As in Table 3 and 4 each material have different $Z_{\mathrm{eq}}$ at various energy levels, so to assign a particular atomic number to each material, mean of $Z_{\mathrm{eq}}$ of each sample at various photon energies is calculated and mean so calculated is treated as the effective atomic number i.e. $Z_{\text {eff }}$ of that material 


$$
\left[Z_{\text {eff }}=\frac{\sum_{B=0.015}^{15.0} Z_{e q}}{25}\right] \text {. }
$$

Values of $Z_{\text {eff }}$ of kaolinite, sand, cascade silt loam and mica are 11.12108, 12.27724, 12.95068 and 13.0056 respectively. This is very helpful in studying the behavior of buildup factor of different chosen materials at fixed penetration depths and fixed photon energy.

To investigate EABF and EBF as a function of $Z_{\text {eff }}$, one penetration depth has been selected, $15 \mathrm{mfp}$, for low energy range i.e. from $0.015-0.15 \mathrm{MeV}$ and for higher energy range which is $1.0-15 \mathrm{MeV}$. From Fig. 9(a) and 10(a) it is analyzed that at $15 \mathrm{mfp}$ and for lower energy range, EABF and EBF shows a decreasing trend as the $Z_{\text {eff }}$ increases. This trend is pronounced for lower $Z_{\text {eff }}$ in comparison to higher $Z_{\text {eff. }}$ Fig. 9 (b) and 10 (b) informs that for high energy range there is practically no change in value of EABF and EBF which implies that attenuation properties of materials taken at higher incident photon energies is not at all effected by their chemical composition.

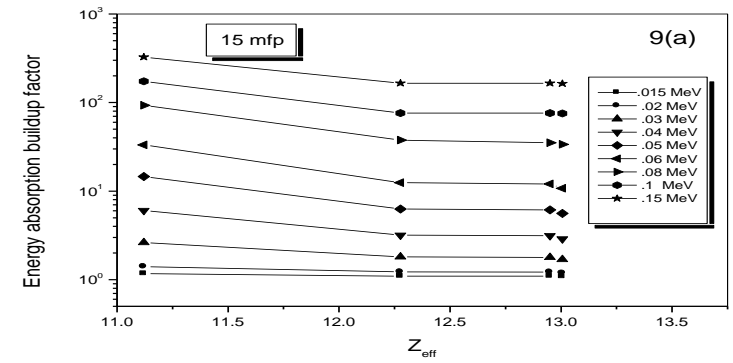

Fig.9 (a) Variation of EABF with effective atomic number $\left(Z_{\text {eff }}\right)$ for energies $0.015-0.15 \mathrm{MeV}$ at 15 $\mathrm{mfp}$.

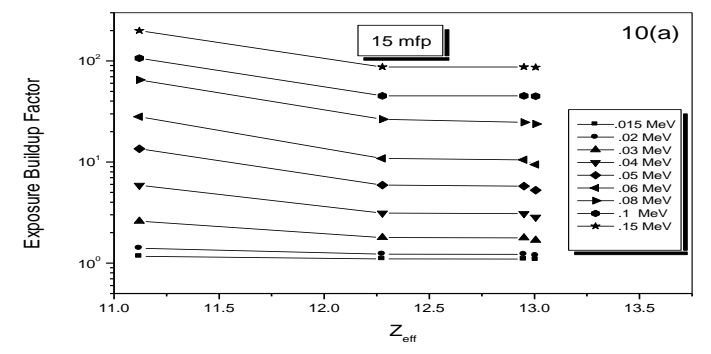

Fig.10 (a) Variation of EBF with effective atomic number $\left(\mathrm{Z}_{\mathrm{eff}}\right)$ for energies $0.015-0.15 \mathrm{MeV}$ at 15 mfp.

\section{Calculation Uncertainty}

The calculated values of EABF and EBF for air have been compared with that EABF and EBF for air in ANSI/ANS [8] data base in the energy region $0.015-15.0 \mathrm{MeV}$ and penetration depth up to $40 \mathrm{mfp}$. From the Fig. $11(a, b)$ it can be clearly seen that our calculated values of air agree well with ANSI/ANS[8]database within a few percent uncertainty. Recently, Asano and Sakamoto have evaluate the buildup factors of heavy concrete and various materials for the shielding wall by using the Monte Carlo simulation code, EGS4[20]. They also compared their calculated values by that of concrete in ANSI/ANS-6.4.3[8] standard reference database. Both the calculations are in good agreement except for the slight differences which may be due to (a) the development of the low energy photon treatments in EGS4 such as K-X ray, L-X ray and Bremsstrahlung. It was shown by Shimizu et al. that the methods based on invariant embedding, G-P fitting and Monte Carlo simulation agree well for 18 low-Z materials within small discrepancies [7], (b) the ANSI/ANS data are based on the calculation result data by using the moments method [21] with parallel beam source and the Monte Carlo code, EGS4 with emission source. The all materials used in the present study consist of low-Z materials. When compared with other available approximations such as Taylor, Berger, and three exponential, the geometricprogression (G-P) fitting seem to reproduce the buildup factors with better accuracy. Harima et al. have shown that the absolute values of maximum deviations of exposure build factors for water in G-P fitting is within 0.5$3 \%$, in Taylor approximation is within 0.4-53.2\%, in Berger approach is within $0.9-42.7 \%$, in three-exponential approach is within $0.4-9.3 \%[22]$. 

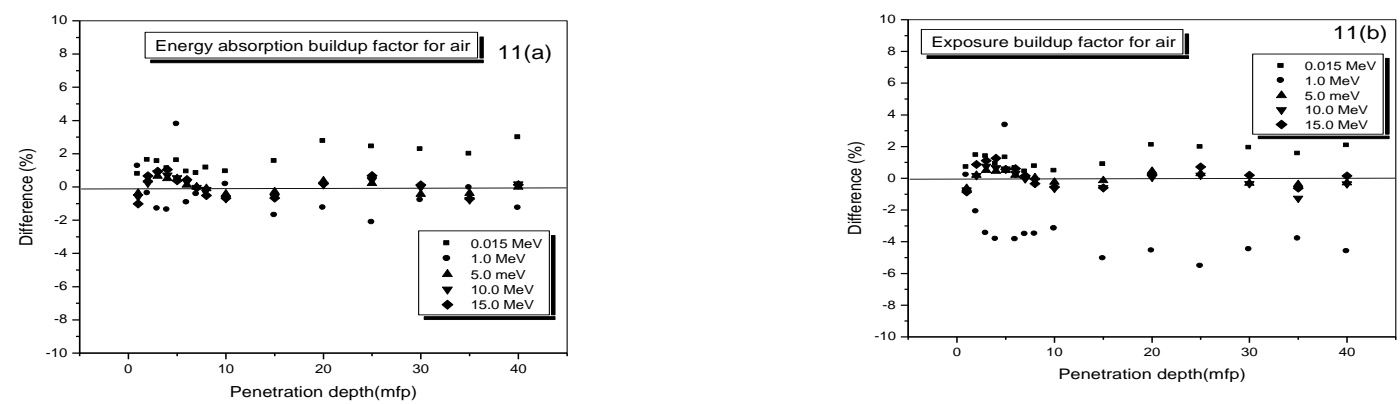

Fig. 11 (a) and (b) Difference (\%) between ANSI data base and present work with respect to the calculated values of EABF and $\mathrm{EBF}$ for Air at some energy levels upto $40 \mathrm{mfp}$.

\section{Conclusion}

What are concluded from the present study are:

Some essential soils and ceramic materials have been investigated in terms of the gamma ray EABF and EBF which are obtained by using the five parameter geometric progression (G-P) fitting formula in the energy region $0.015-15 \mathrm{MeV}$ up to a penetration depth of $40 \mathrm{mfp}$. Significant increase in EABF and EBF have been observed for soils and ceramic materials in energy region of $0.2 \mathrm{MeV}$ approximately, where Compton scattering predominates. The variation of EABF and EBF with incident photon energy seem to be independent of chemical composition of above materials beyond $2.0 \mathrm{MeV}$ At higher energy range 5-15 MeV chemical composition does not affect the variation of EABF and EBF of soils with increase in penetration depths but this does not happen in case of ceramic materials. At lower energy range 0.015-0.2 MeV values of EABF and EBF show decreasing trend with increase in $Z_{\text {eff }}$ but at higher energy range $1.0-15 \mathrm{MeV}$, the values tends to remain constant.

\section{Acknowledgment}

We are grateful to Berger and Hubbell for providing the convenient computer program XCOM with the help of National Institute of Standards and Technology (NIST), Gaithersburg

\section{References}

[1] White, G. R.,The penetration and deffusion of ${ }^{60} \mathrm{Co} \gamma$-rays in water using spherical geometry,Rev. 80, $1950,154$.

[2] Fano, U., $\Gamma$-ray attenuation part II-analysis of penetration,Nucleonics 11, 1953, 55.

[3] P.S. Singh, T. singh, P. Kaur, Ann. Nucl. Eng., 35, 2008, 1093.

[4] Y. Harima,Y.Sakamoto, S. Tanaka, M. kawai, Nucl. Sci. Eng., 94, 1886, 24

[5] Y. Sakamoto, S. Tanaka, Nucl. Sci. Eng., 100, 1988, 33.

[6] A. Shimizu, J. Nucl. Sci. Technol., 39, 2002, 477.

[7] A. Shimizu, T. Onda, Y. Sakamoto, J. Nucl.Sci.Technol., 41, 2004, 413.

[8] ANSI/ANS-6.4.3, gamma ray attenuation coefficient and buildup factors for engineering materials, American Nuclear Society, La Grange Park, Illinois.1991.

[9] Y. Harima, Nucl. Sci. Eng., 83, 1983, 299.

[10] Y. Harima, Radiat. Phys. Chem., 41, 1993, 631.

[11] Mudahar G. S. and Sahota H. S. A new method for simultaneous measurement of soil bulk density and water content., Int. J. Appl. Radiat. Isot., 37, 1986, 563.

[12] Brady N.C. The Nature and properties of soils, $8^{\text {th }}$ edition, 1983, 24.

[13] Bear F.E. Chemistry of the soil, second edition, 1965, 106,89

[14] Brar, G.S., Sidhu, G.S.,Sandhu P.S., Mudahar, G.S., Variation of buildup factors of soil with weight fractions of Iron and silicon.,Appl. Radiat. Isot., 49, 1998, 977-980.

[15] G.S. Sidhu, P.S.Singh, G.S. Mudahar, J. radiol. Prot., 20, 2000, 53.

[16] S.R. Manohara, S.M. Hanagodimath, L.Gerward, K.C. Mittal,Exposure buildup factors of heavy metal oxide glass:A radiation Shield Journal of the Korean Physical Society, 59, no. 2, August 2011, 2039-2042.

[17] M. Singh, G. S. Mudahar,Energy dependence of total photon attenuation coefficients of composite material, Int. J. Appl. Radiat. Isot. (U.S.A.), 43, 1992, 907.

[18] Berger, M.J., Hubbell, J.H., 1987/1999. XCOM: Photon Cross-Sections Database, Web Version 1.2, National Institute of Standards and Technology, Gaithersburg, MD20899, USA. http://physics. nist.gov/xcom (Originally published as NBSIR 87-3597 "XCOM: Photon Cross Sections on a Personal Computer")

[19] T. Singh, N. Kumar, S.P. Singh, Ann. Nucl. Eng., 36, 2009, 114.

[20] Y. Asano, Y. Sakamoto, Gamma Ray buildup factors for heavy Concrete, JAEData/Code 2007-006, 2007.

[21] C.M. Eisenhauer, G.L. Simmons, Nucl. Sci. Eng., 56, 1975.

[22] Y. Harima, Y. Sakamoto, S. Tanaka, M. Kawai, T. Fujita, T. Ishikawa, M. Kinno, K. Hayashi, Y. Matsumoto, T. Nishimura. Japan atomic Energy research Institute (JAERI)-M 86-071, 1986. 